\title{
Biologia Futura: adaptive changes in urban populations
}

\author{
András Liker ${ }^{1}$ \\ Received: 9 October 2019 / Accepted: 17 February 2020 / Published online: 2 March 2020 \\ (c) The Author(s) 2020
}

\begin{abstract}
Cities represent novel environments where altered ecological conditions can generate strong selection pressures leading to the evolution of specific urban phenotypes. Is there evidence for such adaptive changes in urban populations which have colonized their new environments relatively recently? A growing number of studies suggest that rapid adaptations may be widespread in wild urban populations, including increased tolerance to various anthropogenic stressors, and physiological, morphological and behavioural changes in response to the altered resources and predation risk. Some of these adaptive changes are based on genetic differentiation, although other mechanisms, such as phenotypic plasticity and epigenetic effects, are also frequently involved.
\end{abstract}

Keywords Habitat urbanization $\cdot$ Selection pressures $\cdot$ Microevolution $\cdot$ Epigenetic inheritance $\cdot$ Phenotypic plasticity

\section{Background}

Cities are one of the most unnatural habitats in our world. They provide special physical and biological environments for organisms and these differ strongly from conditions in their original habitats. Despite the intensive anthropogenic influences, urban areas can harbour diverse ecological communities that may include, for example, rare plants, breeding populations of wild animals, and even raptors and carnivores that usually avoid humans in their natural habitats (Schilthuizen 2018). Although research on the ecological effects of urbanization has increased exponentially in the last three decades, studies that explicitly focus on evolutionary changes in wild populations of urban plants and animals are emerging only recently (Johnson and Munshi-South 2017; Rivkin et al. 2019). These results suggest that urbanized populations can quickly adapt to their new and changing environments, thus cities may represent unique 'evolutionary experiments' in which some evolutionary processes can be studied more easily than in natural systems. In this kick-off review, I highlight some of the fastest progressing fields in urban evolutionary research. First, I illustrate the

András Liker

andras.liker@gmail.com

1 MTA-PE Evolutionary Ecology Research Group, Department of Limnology, University of Pannonia, Pf. 158, 8200 Veszprém, Hungary diversity of evolutionary responses of urban populations to various selection forces these populations face in the cities. Then, I review recent progresses in the understanding of the mechanisms that can generate urban adaptations (Fig. 1). I use the term 'adaptive change' in a broad sense for phenotypic changes that are advantageous in a new environment regardless whether these are generated by genetic or other mechanisms (Gotthard and Nylin 1995). Note that evolutionary changes include non-adaptive genetic changes, for example due to founder effect or genetic drift. Although nonadaptive evolution may be common in urban populations (Miles et al. 2019), in this review I focus on processes that result in adaptations.

\section{Selection forces in the cities}

There are several well-known characteristics of the urban environment that differ strongly from natural, or at least less-transformed areas surrounding cities. In the following sections I briefly discuss some of these urban characteristics, which can exert strong and sometimes new selection pressures on organisms. I also show examples for how urban populations can respond to these challenges by various adaptations, including changes in behaviour, physiology, and morphological traits. 


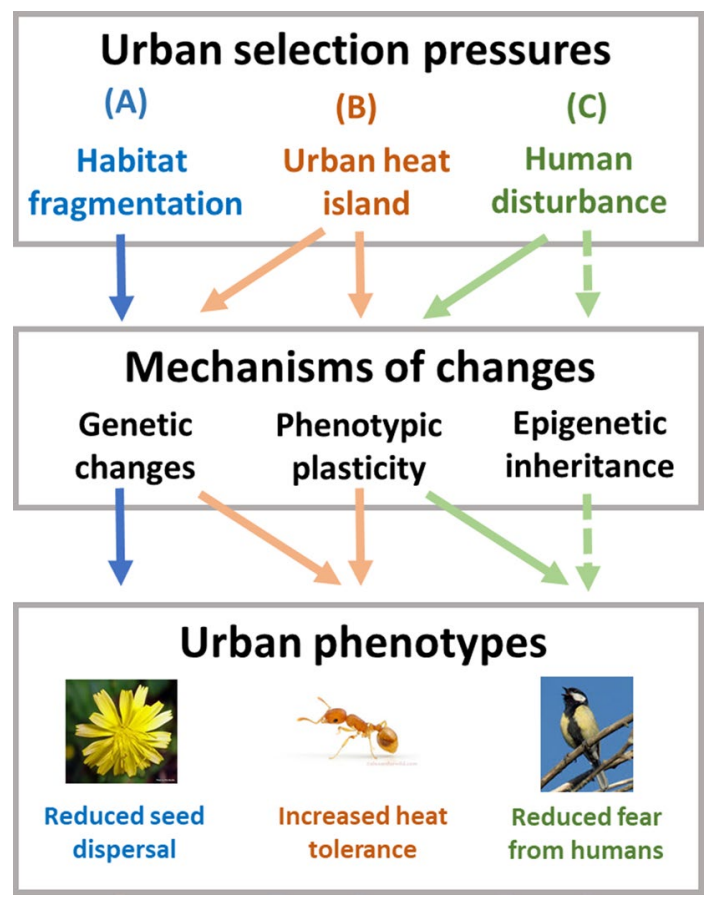

Fig. 1 Examples for selection pressures, mechanisms of changes, and the resulted phenotype in wild urban populations. a In cities, holy hawksbeards produce more non-dispersing seeds in response to the small size and isolation of suitable habitat patches (Cheptou et al. 2008). b In acorn ants, urban populations have altered temperature tolerances, caused by both genetic differentiation and phenotypic plasticity (Diamond et al. 2017). c Birds often reduce their escape response to humans in urban areas, which involves phenotypic plasticity (for example habituation Vincze et al. 2016), but epigenetic effects may also play a role in the development of the urban behavioural phenotype (Riyahi et al. 2015). See text for details

\section{Habitat structure}

One of the defining characteristics of urban sites is the high proportion of built-up areas connected by networks of roads. These and other artificial structures, together with the often contrasting types of vegetated areas (e.g. parks, street tree lines, gardens, lawns) make urban areas fragmented, where suitable habitat patches are isolated. Since survival and successful reproduction of organisms may depend on their movements between patches (e.g. to find food or site for breeding), fragmentation is expected to influence dispersal ability in urban populations. For instance, a small annual weed, the holy hawksbeard (Crepis sancta), produces both dispersing and non-dispersing seeds, and has heritable variation for the proportions of the two seed types. Experiments showed that in fragmented urban areas non-dispersing seeds have $55 \%$ higher chance to land in the habitat patch of the parent plant (i.e. on substrates suitable for germination) than the dispersing form, which often fall on concrete or other unsuitable substrates. This difference in success between the two types of offspring exerts strong selection for producing non-dispersing seed, and accordingly its proportion is significantly increased in urban populations (Cheptou et al. 2008). In other organisms, however, fragmentation may favour increased dispersal ability that help colonizing new areas. For example, in a study of community-level body size distributions, urban communities contained larger species than non-urban communities in those taxa in which body size positively covaries with dispersal ability (e.g. orthopterans and lepidopterans), probably because larger species can mitigate more successfully the low connectivity between suitable habitat patches (Merckx et al. 2018).

Artificial habitat elements can also modify the structural characteristics of the habitat in a way that influences locomotion and hence habitat use. For example, flat and smooth artificial surfaces are more common in cities than in natural sites, which may make movements difficult for animals adapted to move on natural substrates (e.g. on ground or tree trunks or twigs). Recent studies show, for instance, that urban populations of the crested anole (Anolis cristatellus) commonly use manmade perches (e.g. painted walls and glass windows). In these populations, the lizards have longer limbs and toe pads with more lamellae than in non-urban areas. Experiments show that these differences are heritable and the evolved traits increase the locomotor performance of urban lizards on artificial substrates, probably increasing their fitness in this novel habitat (Winchell et al. 2016, 2018).

\section{Microclimate}

Urban areas usually have altered microclimate compared to surrounding non-urban areas, including increased temperature (urban heat island effect, which can be several ${ }^{\circ} \mathrm{C}$ in larger cities). Living in a warmer environment can influence basic biophysical and physiological processes such as metabolic rate, evaporation, and heat transport. These, in turn, may have effects on diverse phenotypic traits including heat/cold tolerance, activity, foraging, optimal body size, and morphological traits involved in insulation. Despite these potentially far-reaching effects, only few studies have tested whether and how urban populations are adapted to the altered thermal environment. One of the most detailed studies so far focused on the thermal tolerance of acorn ants (Temnothorax curvispinosus), and showed in a common garden experiment that some of the urban populations evolved reduced cold tolerance, increased heat tolerance, and a compressed thermal tolerance breadth as compared to rural populations (Diamond et al. 2017). The shifts in tolerance appear to be adaptive, because under warm laboratory temperatures urban populations produce more, whereas rural 
populations produce fewer sexual reproductives (Diamond et al. 2018). The reproductive advantage of heat tolerant/ adapted phenotypes is also documented in the scale insect (Parthenolecanium quercifex), in which population abundance was 13 times higher on trees in the hottest urban areas than in cooler areas. The difference in reproductive rates between $P$. quercifex collected from hot and cooler urban areas persisted in hot (but not cool) greenhouse condition, suggesting that in this insect some demes have either acclimatized or genetically adapted to high temperatures (Meineke et al. 2013). Some community-level phenotypic changes may also be related to increasing temperature along the urbanization gradient. In the study of body size distribution of terrestrial and aquatic arthropods, more urbanized communities generally consisted of smaller species than less urbanized communities in taxa where size is not related to dispersal ability. Smaller body size in these species may be adaptive in the cities because metabolic costs of developing/ maintaining large body size is higher in warmer environments (Merckx et al. 2018).

Interestingly, the altered urban microclimate sometimes may drive changes in the opposite way, resulting in increased cold tolerance in more urbanized areas. In the white clover (Trifolium repens) cyanogenesis protects plants from herbivores, but reduces tolerance for freezing temperatures. In a study of four urban gradients, the frequency of cyanogenic plants within populations decreased towards the urban centres in three cities. The authors suggest that reduced snow cover in cities results in colder minimum winter ground temperatures, which may select against cyanogenesis, i.e. select for increased cold tolerance in inner urban areas (Thompson et al. 2016).

\section{Pollution}

One of the earliest demonstration of evolutionary changes in natural populations was provided by the increased survival and associated spread of dark-coloured form of the peppered moth (Biston betularia) in industrial areas of England, where air pollution altered the effectiveness of colour mimicry in different colour phenotypes (Rivkin et al. 2019). The various types of pollutions have remained important environmental stressors in cities, often inducing marked changes in traits of urban organisms. For instance, water bodies at some urban estuaries on the U.S. Atlantic coast are strongly contaminated with persistent industrial pollutants such as polychlorinated biphenyl (PCB) that may reach more than 10,000 times higher concentration than that of the threshold for adverse effects. Populations of the Atlantic killifish (Fundulus heteroclitus) living in such estuaries have rapidly adapted to the normally lethal levels of pollution, and now are able to tolerate several thousands higher PCB concentrations than populations living in non-contaminated waters. Recent research showed that strong natural selection in four contaminated killifish populations resulted in similar genetic changes that contribute to the development of PCBtolerant phenotypes (Reid et al. 2016).

Besides chemicals, noise and light pollutions are also constant elements of the urban environment. One of the best studied phenotypic changes associated with increased urban noise is the altered acoustic signalling by some songbirds. In great tits (Parus major), males studied in 11 big European cities consistently produced songs that were shorter and faster and had higher minimum frequencies than songs produced by males in nearby forests. Since anthropogenic noise is generally biased towards lower frequencies, these song characteristics are assumed to reduce the masking effects of noise on the birds' acoustic signals (Slabbekoorn and den Boer-Visser 2006). As predicted by this hypothesis, female great tits appear to react more strongly to high-frequency than to low-frequency song types in noisy environments, although the direct demonstration of fitness benefits of the urban song phenotype is still lacking (Slabbekoorn 2013).

\section{Food and nutrients}

Altered physical conditions (e.g. microclimate, pollution) and human activities such as using pesticides, irrigation, fertilizers, and directly providing food for some species, can drastically alter types and amount of nutrients and food available for urban organisms. For example, caterpillar populations that provide a significant part of the diet for many insectivorous animals in European forests during spring and summer can have up to 20-fold biomass reduction in urban tree canopies compared to forest trees (Seress et al. 2018). Such fundamental changes in food sources can induce adaptations at several levels. First, organisms can respond quickly by modifying their food preference and feeding behaviour, which has been often documented for urban animals. For example, in urban streams across the Hawaiian archipelago, the native goby species Awaous stamineus shifts its diets from algae to greater amounts of exotic invertebrates, elevating its trophic position in the food web. This dietary flexibility seems adaptive, because $A$. stamineus can maintain similar body condition and resilient population density across the urbanisation gradient, whereas the densities of other native gobies decline sharply with urbanisation (Lisi et al. 2018).

Altered diets may also induce morphological changes. House finches (Carpodacus mexicanus) that live in adjacent desert and urban areas forage on seeds that differ in size and shell hardness, and require different bite forces and bill morphologies for processing. Accordingly, desert finches have smaller bills and weaker bite force than urban finches. The developmental basis of this divergence includes accelerated bill tissue transformation and earlier and higher 
level expression of bone morphogenetic proteins in the urban than in desert finches. Urban and desert populations are also distinct genetically (Badyaev et al. 2008). Similarly, a study of great tits found ongoing selection on genes for bill morphology (for example on the collagen gene COL4A5), and that bill length and $C O L 4 A 5$ variation were associated with usage of bird feeders, suggesting that longer bills in this species may have evolved as a response to supplementary feeding (Bosse et al. 2017).

Finally, several recent studies suggest evidence for molecular adaptations for digesting altered food types in urban habitats, such as leftovers from human waste or stored grains. A genomic study in the house sparrows (Passer domesticus) estimates that the species had a population expansion 6000 years ago, that appears to coincide with the spread of agriculture in Eurasia. Genomic regions with the strongest signatures for recent, positive selection in sparrows include the candidate gene $A M Y 2 A$, part of the amylase gene family which is linked to adaptation to high-starch diets, presumably in response to feeding on human-processed foods (Ravinet et al. 2018).

\section{Predators and parasites}

Due to their strong effects on survival, predators, parasites and pathogens can generate strong natural selection in wild populations. Although habitat urbanization is likely to alter predator and parasite communities, adaptations in response to such changes in urban preys and host species are relatively rarely documented (except for escape responses to humans, see below). This may be related, at least in part, to the variable and complex relationships between urbanization and these selection pressures. Firstly, the density of vertebrate predators may either increase or decrease along the urban gradient, depending on both the predator species and cities in question (Fischer et al. 2012). Secondly, although the overall predator density (especially for mesopredators) may be higher in some urban areas than in natural habitats, this not necessarily translates into higher predation risks for urban preys because predators may use alternative food types such as leftovers from human waste and consequently reduce their hunting activity (Fischer et al. 2012). For example, the density of domestic cats (Felis catus) increases with habitat urbanization, but they take fewer preys in cities than in non-urbanized areas (Fischer et al. 2012). Thus, whether and how urbanization influences predation risk is likely specific for a given predator-prey system, and also can vary between cities. For example, urban house sparrows and great tits from the same geographic areas showed stronger and weaker responses, respectively, to experimental exposure to sparrowhawk (Accipiter nisus, one of their most common predators) than their non-urban conspecifics, suggesting contrasting urban predation risk for these species (Seress et al. 2011; Vincze et al. 2019).

One candidate trait that may have changed in response to reduced urban predation and parasitism risks is the mating call of male túngara frogs (Physalaemus pustulosus). In this Neotropical species, production of complex calls increases the males' mating success, but at the same time also increases mortality risk because predators and parasites, as bats and midges are also preferentially attack males with that call type. Males in urban populations produce more complex calls and at a higher rate than forest males. Playback experiments showed that this urban phenotype attract more females than the forest phenotype, but avoid the costs imposed by eavesdropping bats and midges because these are rare in urban areas. Although the underlying mechanism of this phenotypic change is not known, it is likely that the most important selective advantage of urban males is the absence of urban predators and parasites (Halfwerk et al. 2019).

Similarly, a strong signature for adaptive changes in response to pathogen exposure was found in urban human populations. Infectious disease has been a frequent cause of mortality through human history, and increased infectious disease load is predicted for urban-living populations due to increases in human population density, pathogen mobility, and pathogen exposure. In a study of 12 cities worldwide with settlement time spanning from $6000 \mathrm{BC}$ to $1919 \mathrm{AD}$, the frequency of alleles conferring resistance to pathogens such as tuberculosis and leprosy increased strongly with the age of the cities, explaining approximately $50 \%$ of the variance in allele frequency. This result suggests directional selection for the resistant allele by pathogens associated with urban life, of which probably tuberculosis has been the most important selective agent (Barnes et al. 2011).

\section{Human disturbance}

Human presence and activities are ubiquitous in urbanized areas. Wild animals often respond to humans as potential predators, for example by fleeing or hiding, but these antipredator responses have costs in terms of reduced time for feeding or parental care which ultimately may reduce fitness (Frid and Dill 2002). Thus, when humans do not pose real danger, animals can benefit from tolerating the proximity and activity of people. Since people often have neutral or positive attitude towards wild animals in cities, reducing escape responses to humans could be adaptive.

In line with this expectation, studies frequently found more disturbance-tolerant phenotypes in urban than in natural habitats (Møller 2008; Samia et al. 2015). Increased tolerance towards humans is most often demonstrated by reduced flight initiation distance when approached by a human observer (FID, a widely accepted proxy for 
risk-taking), a pattern consistent among a high number of species (Blumstein 2019). Disturbance tolerance has a genetic basis, as indicated by selection experiments that successfully produced tolerant lines (Agnvall et al. 2018) and by the heritability of FID in wild populations (Bize et al. 2012; Møller 2014; Carrete et al. 2016). Furthermore, disturbance tolerance appears to be linked to candidate genes (e.g. DRD4 and SERT; Garamszegi et al. 2014; Van Dongen et al. 2015; Holtmann et al. 2016, which also exhibit differences in allele frequencies between urban and non-urban populations (Mueller et al. 2013; Riyahi et al. 2015, 2017; Van Dongen et al. 2015). These evidences suggest that developing a tolerant phenotype may be an adaptive response to reduced danger posed by people in cities. However, the fitness consequence of this behavioural change is poorly explored. In a correlative study of barn swallows (Hirundo rustica), longer FID was associated with higher breeding success in open farmland habitat, although the relationship was not tested in urban areas (Møller 2014). Another study of the parthenogenetic mourning geckos (Lepidodactylus lugubris) showed that the more risk-taking behavioural phenotype of the socalled A-clone (that spends less time hiding) is associated with quicker initiation of foraging and higher feeding success than the more shy phenotype of $B$-clone. The study concludes that the ability of $A$-clone to exploit limited food resources helps it spread in human-modified landscapes where these geckos often need to forage on open surfaces far from shelter, like on walls of buildings (Short and Petren 2008).

\section{Mechanisms of urban adaptations}

Phenotypic differences between populations can be produced by several mechanisms, including phenotypic plasticity, epigenetic effects, and genetic changes due to natural selection and/or non-random gene flow. As demonstrated by a growing number of experimental and genetic evidence, all of these mechanisms may play a role in adaptations to urban environments.

\section{Phenotypic plasticity}

The development of phenotypic traits is often flexible and influenced by the environment experienced during ontogeny. For example behavioural traits can be modified by learning. Other mechanisms can similarly produce plasticity in morphological and physiological traits in response to environmental variation. Phenotypic plasticity can be particularly beneficial in novel or changing environment (such as cities), where it may provide the basis for quick responses. Furthermore, adjustments by phenotypic plasticity is also important because it can promote later genetic changes by genetic assimilation (Lande 2009).

There are several examples for the role of phenotypic plasticity in generating differences between urban and rural populations. Glucocorticoids allow animals to respond to environmental changes through their effects on development that can lead to modified phenotypes. In house wrens (Troglodytes aedon), urban birds consistently have higher baseline corticosterone levels than rural birds. Cross-fostering experiments showed that freshly hatched ( 0 days old) urban wrens already have higher corticosterone concentrations than rural nestlings. However, rural offspring reared in urban broods significantly increased their corticosterone levels, similarly to those of urban offspring. These results suggest that the urban-rural difference in baseline corticosterone level may have a genetic component, but plasticity can modify the corticosterone phenotype in response to the environment experienced during offspring development (Ouyang et al. 2019).

Phenotypic plasticity is also involved in the development of thermal tolerance in urban acorn ants (discussed above). Common garden experiments showed that urban ants had higher thermal tolerances than rural ants regardless of rearing temperature. However, ants reared in warmer temperature exhibited higher tolerances than ants reared in cooler temperature regardless of their original habitat. These results show that in this species both genetic differences and phenotypic plasticity contributes to the formation of the heat-tolerant urban phenotype. Interestingly, this study also suggests that the plasticity itself has evolved during urbanization, since the strength of the response to warmer and colder rearing environments differed between rural and urban populations (Diamond et al. 2017). A similar experiment suggests the involvement of phenotypic plasticity in the change of song types in urban birds in response to noise pollution (Moseley et al. 2018). Behavioural plasticity can also influence disturbance tolerance. This was demonstrated in an experiment with captive house sparrows in which urban birds habituated more quickly to repeated disturbances than rural birds, despite of their similar initial responses to the first disturbance (Vincze et al. 2016).

\section{Epigenetic effects}

A further mechanism allowing fast response by urban organisms is epigenetic inheritance, which involves heritable changes in gene expression that occur without changes in the DNA sequence. Since stable epigenetic changes in the germline can result in transgenerational inheritance, this mechanism enable parents to pass their modified gene expression profile to the offspring that can develop a phenotype adapted to the expected environment (Ledón-Rettig et al. 2013). A recent model shows that some epigenetically mediated adaptive changes are more likely to evolve when 
(1) populations are subdivided between habitats differing in the direction of selection and (2) have moderate migration rates (Greenspoon and Spencer 2018). These conditions may be frequently met in species that have both urban and rural populations (Rivkin et al. 2019).

Only a few studies have investigated so far whether urban adaptations involve epigenetic mechanisms. Evidence suggest the possibility of such epigenetic effects in the development of the disturbance-tolerant/explorative behavioural phenotypes. First, a selection experiment showed that the level of DNA methylation, which is one of the main mechanisms of epigenetic inheritance, can change quickly in response to artificial selection for tolerance to human disturbance (Bélteky et al. 2018). Furthermore, studies conducted in wild populations also suggest that (1) DNA methylation can differ between urban and non-urban populations including DRD4 and SERT loci, and (2) differences in methylation of the $D R D 4$ locus is associated with behavioural differences in at least one avian species, the great tit (Riyahi et al. 2015; Verhulst et al. 2016). Another study that compared transcriptomes between urban and a rural great tit population found strong habitat differences in gene expression profiles, and suggested a key role for epigenetic mechanisms in mediating the observed variation in gene expression (Watson et al. 2017). A comparison of urban and rural populations of two species of Darwin finches (Geospiza fortis and G. fuliginosa) also detected striking differences in DNA methylation (McNew et al. 2017). In contrast, no habitat differences were found in the frequency of methylation in the túngara frog (Garcia et al. 2019).

\section{Genetic changes}

An increasing amount of evidence suggests that many phenotypic changes we see in urban organisms are consequences of adaptive evolution that changes the genetic composition of populations towards genotypes which results in phenotypes with increased fitness. For example, several of the studies cited above inferred experimentally that (1) the phenotypic differences between urban and rural populations have a genetic basis (e.g. persists in offspring raised in common environment, in some cases for several generations), and (2) the urban phenotype provides selective advantage to its bearer in urban environment as opposed to the non-urban phenotype (see for example seed dispersal in hawksbeards, thermal tolerance shift in ants, pollution tolerance in killfish, and male mating call in túngara frogs; Cheptou et al. 2008; Reid et al. 2016; Diamond et al. 2018; Halfwerk et al. 2019).

Urban ecologists are increasingly exploiting population genomic tools to identify signatures of natural selection. For example, a landscape genomic study of white-footed mice (Peromyscus leucopus) found evidence for selection associated with urban habitats on several genomic regions. Many of the identified candidate genes have functions related to the metabolism and transport of lipids and carbohydrates, suggesting that selection acts on metabolic pathways in mice due to their novel diets in cities (Harris and Munshi-South 2017). Similar studies in other species indicate positive selection on candidate genes linked to various functions that may be involved in urban adaptations, including metabolism, detoxification, oxidative stress, heat tolerance, immunity, morphology, and behaviour (Reid et al. 2016; Ravinet et al. 2018; Theodorou et al. 2018; DeCandia et al. 2019).

These studies also highlight that some evolutionary changes in urban populations can be remarkably fast. In the case of the holy hawksbeard, for example, a quantitative genetic model for the change in dispersal strategy was consistent with a short-term evolution scenario that occurred over 5-12 generations (Cheptou et al. 2008). In the case of acorn ants, researchers estimated 7-20 generations of urban history for the studied populations that developed heritable changes in thermal tolerance (Diamond et al. 2017). Since many species have colonized urban areas relatively recently, their phenotypic differences from rural populations may frequently be the result of similarly rapid evolutionary changes.

We should note again, however, that not all genetic changes observed in urban populations are the consequences of adaptive evolution. These populations may become genetically distinct from their non-urban ancestors due to several non-adaptive processes including, for example, random genetic drifts and founder effects, especially when the number of individuals that initially colonize a city is small. A recent review found that more than $90 \%$ of the studies detected an association of urbanization with patterns of genetic drift or gene flow, suggesting a consistent and significant effect of urbanization on non-adaptive evolution (Miles et al. 2019).

\section{Conclusions for future biology}

As demonstrated by the above studies, adaptive changes are frequent in urban populations, and even species that only have a relatively short urban history can show signs of rapid and ongoing changes. This offers many opportunities for urban evolutionary ecologist for getting a better understanding of both the general processes of adaptive evolution, and also the specific characteristics of adaptations to urbanization (Rivkin et al. 2019).

The main advantages of investigating evolution in urban populations include (1) the often drastic environmental changes that generate strong selection forces, (2) the availability of historical records for time of colonization by urban 
species that can provide temporal information on the process of adaptation, (3) the possibility to study replicated evolutionary events by running parallel studies in multiple cities, and (4) the easy access to wild urban populations that makes some studies more feasible in cities than in non-urban areas. By these factors facilitating research, urban habitats may quickly become one of the best understood evolutionary systems.

There are interesting similarities between urban adaptations and the process of domestication that may also deserve further research. For example, in animals, both processes may involve selection for tameness and the successful exploitation of anthropogenic food (Axelsson et al. 2013). Results on behavioural, reproductive and genetic changes in currently urbanizing populations may help understand the early steps of domestication, for example in dogs and cats (Newsome et al. 2017). Conversely, knowledge about the domestication process may help predict future genetic and phenotypic changes in wild urban populations that are already in strong commensal relationships with humans (Newsome et al. 2017). For instance, we can see several birds and mammals that coexist with humans in the cities as semi-domesticated animals, and it is an intriguing question whether and when the process could lead to the development of even closer relationships (e.g. stronger dependence for animals and/or more purposeful use by people).

We can expect an especially rapid advance in the understanding of genetic structuring of populations along the urbanization gradient, that has important effect on the nature and tempo of urban evolutionary changes (Johnson and Munshi-South 2017; Miles et al. 2019; Rivkin et al. 2019). With the availability of advanced genomic, epigenetic and bioinformatic methods, it is increasingly possible to explore the relative importance of different evolutionary mechanisms in urban adaptations. For example, epigenetic processes are frequently suggested as a mechanism of rapid phenotypic changes (e.g. Watson et al. 2017), although it has been investigated only in a limited number of studies (Riyahi et al. 2015; McNew et al. 2017). Finally, genomic studies will continue to highlight the likely targets of selection (e.g. candidate genes), which will help us uncover the molecular bases of urban adaptations.

Acknowledgements Open access funding provided by University of Pannonia (PE). I am grateful to current and past members of the MTAPE Evolutionary Ecology Research Group for the stimulating discussions of urban evolutionary topics.

Funding This work was supported by the grant K132490 from the National Research, Development and Innovation Office (NKFIH).

Open Access This article is licensed under a Creative Commons Attribution 4.0 International License, which permits use, sharing, adaptation, distribution and reproduction in any medium or format, as long as you give appropriate credit to the original author(s) and the source, provide a link to the Creative Commons licence, and indicate if changes were made. The images or other third party material in this article are included in the article's Creative Commons licence, unless indicated otherwise in a credit line to the material. If material is not included in the article's Creative Commons licence and your intended use is not permitted by statutory regulation or exceeds the permitted use, you will need to obtain permission directly from the copyright holder. To view a copy of this licence, visit http://creativecommons .org/licenses/by/4.0/.

\section{References}

Agnvall B, Bélteky J, Katajamaa R, Jensen P (2018) Is evolution of domestication driven by tameness? A selective review with focus on chickens. Appl Anim Behav Sci 205:227-233

Axelsson E, Ratnakumar A, Arendt ML, Maqbool K, Webster MT, Perloski M et al (2013) The genomic signature of dog domestication reveals adaptation to a starch-rich diet. Nature 495:360-364

Badyaev AV, Young RL, Oh KP, Addison C (2008) Evolution on a local scale: developmental, functional, and genetic bases of divergence in bill form and associated changes in song structure between adjacent habitats. Evolution 62:1951-1964

Barnes I, Duda A, Pybus OG, Thomas MG (2011) Ancient urbanization predicts genetic resistance to tuberculosis. Evolution 65:842-848

Bélteky J, Agnvall B, Bektic L, Höglund A, Jensen P, Guerrero-Bosagna $C$ (2018) Epigenetics and early domestication: differences in hypothalamic DNA methylation between red junglefowl divergently selected for high or low fear of humans. Genet Sel Evol 50:1-10

Bize P, Diaz C, Lindström J (2012) Experimental evidence that adult antipredator behaviour is heritable and not influenced by behavioural copying in a wild bird. Proc R Soc B Biol Sci 279:1380-1388

Blumstein DT (2019) What chasing birds can teach us about predation risk effects: past insights and future directions. J Ornithol 160:587-592

Bosse M, Spurgin LG, Laine VN, Cole EF, Firth JA, Gienapp P et al (2017) Recent natural selection causes adaptive evolution of an avian polygenic trait. Science 358:365-368

Carrete M, Martínez-Padilla J, Rodríguez-Martínez S, Rebolo-Ifrán N, Palma A, Tella JL (2016) Heritability of fear of humans in urban and rural populations of a bird species. Sci Rep 6:1-6

Cheptou P-O, Carrue O, Rouifed S, Cantarel A (2008) Rapid evolution of seed dispersal in an urban environment in the weed Crepis sancta. Proc Natl Acad Sci USA 105:3796-3799

DeCandia AL, Brzeski KE, Heppenheimer E, Caro CV, Camenisch G, Wandeler P et al (2019) Urban colonization through multiple genetic lenses: the city-fox phenomenon revisited. Ecol Evol 9:2046-2060

Diamond SE, Chick L, Perez A, Strickler SA, Martin RA (2017) Rapid evolution of ant thermal tolerance across an urban-rural temperature cline. Biol J Linn Soc 121:248-257

Diamond SE, Chick LD, Perez A, Strickler SA, Martin RA (2018) Evolution of thermal tolerance and its fitness consequences: parallel and non-parallel responses to urban heat islands across three cities. Proc R Soc B Biol Sci 285:20180036

Fischer JD, Cleeton SH, Lyons TP, Miller JR (2012) Urbanization and the predation paradox: the role of trophic dynamics in structuring vertebrate communities. Bioscience 62:809-818 
Frid A, Dill L (2002) Human-caused disturbance stimuli as a form of predation risk. Ecol Soc 6:11

Garamszegi LZ, Mueller JC, Markó G, Szász E, Zsebok S, Herczeg $\mathrm{G}$ et al (2014) The relationship between DRD4 polymorphisms and phenotypic correlations of behaviors in the collared flycatcher. Ecol Evol 4:1466-1479

Garcia MJ, Rodríguez-Brenes S, Kobisk A, Adler L, Ryan MJ, Taylor RC et al (2019) Epigenomic changes in the túngara frog (Physalaemus pustulosus): possible effects of introduced fungal pathogen and urbanization. Evol Ecol 33:671-686

Gotthard K, Nylin S (1995) Adaptive plasticity and plasticity as an adaptation: a selective review of plasticity in animal morphology and life history. Oikos 74:3-17

Greenspoon PB, Spencer HG (2018) The evolution of epigenetically mediated adaptive transgenerational plasticity in a subdivided population. Evolution 72:2773-2780

Halfwerk W, Blaas M, Kramer L, Hijner N, Trillo PA, Bernal XE et al (2019) Adaptive changes in sexual signalling in response to urbanization. Nat Ecol Evol 3:374-380

Harris SE, Munshi-South J (2017) Signatures of positive selection and local adaptation to urbanization in white-footed mice (Peromyscus leucopus). Mol Ecol 26:6336-6350

Holtmann B, Grosser S, Lagisz M, Johnson SL, Santos ESA, Lara CE et al (2016) Population differentiation and behavioural association of the two "personality" genes DRD4 and SERT in dunnocks (Prunella modularis). Mol Ecol 25:706-722

Johnson MTJ, Munshi-South J (2017) Evolution of life in urban environments. Science 358:eaam8327

Lande R (2009) Adaptation to an extraordinary environment by evolution of phenotypic plasticity and genetic assimilation. J Evol Biol 22:1435-1446

Ledón-Rettig CC, Richards CL, Martin LB (2013) Epigenetics for behavioral ecologists. Behav Ecol 24:311-324

Lisi PJ, Childress ES, Gagne RB, Hain EF, Lamphere BA, Walter RP et al (2018) Overcoming urban stream syndrome: trophic flexibility confers resilience in a Hawaiian stream fish. Freshw Biol 63:492-502

McNew SM, Beck D, Sadler-Riggleman I, Knutie SA, Koop JAH, Clayton DH et al (2017) Epigenetic variation between urban and rural populations of Darwin's finches. BMC Evol Biol 17:1-14

Meineke EK, Dunn RR, Sexton JO, Frank SD (2013) Urban warming drives insect pest abundance on street trees. PLoS ONE 8:e59687

Merckx T, Souffreau C, Kaiser A, Baardsen LF, Backeljau T, Bonte $\mathrm{D}$ et al (2018) Body-size shifts in aquatic and terrestrial urban communities. Nature 558:113-116

Miles LS, Rivkin LR, Johnson MTJ, Munshi-South J, Verrelli BC (2019) Gene flow and genetic drift in urban environments. Mol Ecol 28:4138-4151

Møller AP (2008) Flight distance of urban birds, predation, and selection for urban life. Behav Ecol Sociobiol 63:63-75

Møller AP (2014) Life history, predation and flight initiation distance in a migratory bird. J Evol Biol 27:1105-1113

Moseley DL, Derryberry GE, Phillips JN, Danner JE, Danner RM, Luther DA et al (2018) Acoustic adaptation to city noise through vocal learning by a songbird. Proc R Soc B Biol Sci 285:20181356

Mueller JC, Partecke J, Hatchwell BJ, Gaston KJ, Evans KL (2013) Candidate gene polymorphisms for behavioural adaptations during urbanization in blackbirds. Mol Ecol 22:3629-3637

Newsome TM, Fleming PJS, Dickman CR, Doherty TS, Ripple WJ, Ritchie EG et al (2017) Making a new dog? Bioscience 67:374-381

Ouyang JQ, Baldan D, Munguia C, Davies S (2019) Genetic inheritance and environment determine endocrine plasticity to urban living. Proc R Soc B Biol Sci 286:20191215

Ravinet M, Elgvin TO, Trier C, Aliabadian M, Gavrilov A, Sætre G-P (2018) Signatures of human-commensalism in the house sparrow genome. Proc R Soc B Biol Sci 285:20181246
Reid NM, Proestou DA, Clark BW, Warren WC, Colbourne JK, Shaw JR et al (2016) The genomic landscape of rapid repeated evolutionary adaptation to toxic pollution in wild fish. Science 354:1305-1308

Rivkin LR, Santangelo JS, Alberti M, Aronson MFJ, de Keyzer CW, Diamond SE et al (2019) A roadmap for urban evolutionary ecology. Evol Appl 12:384-398

Riyahi S, Björklund M, Mateos-Gonzalez F, Senar JC (2017) Personality and urbanization: behavioural traits and DRD4 SNP830 polymorphisms in great tits in Barcelona city. J Ethol 35:101-108

Riyahi S, Sánchez-Delgado M, Calafell F, Monk D, Senar JC (2015) Combined epigenetic and intraspecific variation of the DRD4 and SERT genes influence novelty seeking behavior in great tit Parus major. Epigenetics 10:516-525

Samia DSM, Nakagawa S, Nomura F, Rangel TF, Blumstein DT (2015) Increased tolerance to humans among disturbed wildlife. Nat Commun 6:1-8

Schilthuizen M (2018) Darwin comes to town: How the urban jungle drives evolution. Picador, New York

Seress G, Bókony V, Heszberger J, Liker A (2011) Response to predation risk in urban and rural house sparrows. Ethology 117(10):896-907

Seress G, Hammer T, Bókony V, Vincze E, Preiszner B, Pipoly I et al (2018) Impact of urbanization on abundance and phenology of caterpillars and consequences for breeding in an insectivorous bird. Ecol Appl 28:1143-1156

Short KH, Petren K (2008) Boldness underlies foraging success of invasive Lepidodactylus lugubris geckos in the human landscape. Anim Behav 76:429-437

Slabbekoorn H (2013) Songs of the city: noise-dependent spectral plasticity in the acoustic phenotype of urban birds. Anim Behav 85:1089-1099

Slabbekoorn H, den Boer-Visser A (2006) Cities change the songs of birds. Curr Biol 16:2326-2331

Theodorou P, Radzevičiūtė R, Kahnt B, Soro A, Grosse I, Paxton RJ (2018) Genome-wide single nucleotide polymorphism scan suggests adaptation to urbanization in an important pollinator, the red-tailed bumblebee (Bombus lapidarius L.). Proc R Soc B Biol Sci 285(1877):20172806

Thompson KA, Renaudin M, Johnson MTJ (2016) Urbanization drives the evolution of parallel clines in plant populations. Proc R Soc B Biol Sci 283:20162180

Van Dongen WFD, Robinson RW, Weston MA, Mulder RA, Guay PJ (2015) Variation at the DRD4 locus is associated with wariness and local site selection in urban black swans. BMC Evol Biol 15:1-11

Verhulst EC, Mateman AC, Zwier MV, Caro SP, Verhoeven KJF, Van Oers K (2016) Evidence from pyrosequencing indicates that natural variation in animal personality is associated with DRD4 DNA methylation. Mol Ecol 25:1801-1811

Vincze E, Papp S, Preiszner B, Seress G, Bókony V, Liker A (2016) Habituation to human disturbance is faster in urban than rural house sparrows. Behav Ecol 27:1304-1313

Vincze E, Pipoly I, Seress G, Preiszner B, Papp S, Németh B et al (2019) Great tits take greater risk toward humans and sparrowhawks in urban habitats than in forests. Ethology 125:686-701

Watson H, Videvall E, Andersson MN, Isaksson C (2017) Transcriptome analysis of a wild bird reveals physiological responses to the urban environment. Sci Rep 7:44180

Winchell KM, Maayan I, Fredette JR, Revell LJ (2018) Linking locomotor performance to morphological shifts in urban lizards. Proc R Soc B Biol Sci 285:20180229

Winchell KM, Reynolds RG, Prado-Irwin SR, Puente-Rolón AR, Revell LJ (2016) Phenotypic shifts in urban areas in the tropical lizard Anolis cristatellus. Evolution 70:1009-1022 